\title{
Avaliação da adição de resíduos de vidro sodo-cálcico e erva-mate em matriz cerâmica
}

\section{(Evaluation of the addition of soda-lime glass and yerba mate wastes in ceramic matrix)}

\author{
A.R.A.Scharnberg1, A. V.Preibbnow', S.Arcaro ${ }^{2 *}$, R. M.da Silva ${ }^{3}$, \\ P.A.M.dos Santos ${ }^{3}$, T. M. Basegio ${ }^{2}$,A.A.L.Rodriguez $z^{3,4}$ \\ ${ }^{1}$ Universidade de Santa Cruz do Sul, Santa Cruz do Sul, RS, Brasil \\ ${ }^{2}$ Universidade Federal do Rio Grande do Sul, Departamento de Materiais, Laboratório de Materiais Cerâmicos, \\ Av. Osvaldo Aranha 99, 90035-190, Porto Alegre, RS, Brasil \\ ${ }^{3}$ Universidade de Santa Cruz do Sul, Programa de Pós-Graduação em Tecnologia Ambiental, \\ Santa Cruz do Sul, RS, Brasil \\ ${ }^{4}$ Universidade de Santa Cruz do Sul, Departamento de Engenharia, Arquitetura e Ciências Agrárias, \\ Santa Cruz do Sul, RS, Brasil
}

\begin{abstract}
Resumo
O presente trabalho avaliou os efeitos da adição de resíduos de vidro sodo-cálcico e de erva-mate sobre a absorção de água, porosidade e resistência mecânica de um material cerâmico. Os pós homogeneizados foram compactados por prensagem uniaxial e submetidos a queima de 900 e $1100{ }^{\circ} \mathrm{C}$ a $2{ }^{\circ} \mathrm{C} \cdot \mathrm{min}^{-1}$. Os resultados mostraram que a adição de vidro e erva-mate à argila produziu materiais cerâmicos com retração linear entre 0,3 e $6 \%$, absorção de água entre 5,3 e $34 \%$, porosidade aparente de até $41 \%$ e resistência mecânica entre 0,5 e $20 \mathrm{MPa}$. Os materiais queimados a 1100 ${ }^{\circ} \mathrm{C}$ foram os que obtiveram as melhores combinações de propriedades, podendo ser aplicados na produção de blocos, telhas ou revestimento cerâmico de acordo com as necessidades específicas da aplicação.
\end{abstract}

Palavras-chave: valoração de resíduos, erva-mate, vidro sodo-cálcico.

\begin{abstract}
The present work evaluated the effects of the addition of soda-lime glass and yerba mate wastes on the water absorption, porosity and mechanical resistance of a ceramic material. The homogenized powders were compacted by uniaxial pressing and subjected to firing at 900 and $1100{ }^{\circ} \mathrm{C}$ at $2{ }^{\circ} \mathrm{C} . \mathrm{min}^{-1}$. The results showed that the addition of sodalime glass and yerba mate to the clay produced ceramic materials with linear shrinkage between 0.3 and 6\%, water absorption between 5.3 and 34\%, apparent porosity of up to $41 \%$ and mechanical strength between 0.5 and $20 \mathrm{MPa}$. The materials fired at $1100^{\circ} \mathrm{C}$ resulted in the best combinations of properties and can be applied in the production of blocks, roof tiles or ceramic tiles according to the specific needs of the application.
\end{abstract}

Keywords: waste valorization, yerba mate, soda-lime glass.

\section{INTRODUÇÃO}

A busca por métodos que visem a redução, reutilização e reciclagem de resíduos na sociedade contemporânea vem sendo amplamente enfatizada, principalmente devido à crescente preocupação com as questões ambientais, bem como a grande influência que elas propiciam na qualidade de vida do homem. Deste modo, o aperfeiçoamento e desenvolvimento de novas tecnologias sustentáveis se

*sabrinarcaro@yahoo.com.br

(D) https://orcid.org/0000-0002-0668-7689 tornam indispensáveis, aumentando consequentemente os estudos sobre a possibilidade da utilização de resíduos como materiais que são utilizados como matéria-prima para a confecção de novos produtos, diminuindo a quantidade de passivos ambientais, além de reduzir a extração de recursos naturais $[1,2]$. Grandes esforços em pesquisa estão sendo realizados para o estudo de novas matérias-primas e o aprimoramento do processamento dos materiais cerâmicos. Vale destacar que a indústria de materiais cerâmicos investe em pesquisas de recursos minerais alternativos. Um destes recursos é a busca de matérias-primas que possuem maior viabilidade econômica, sem prejudicar a qualidade final do 
produto [3]. Desta forma, o desenvolvimento de estudos voltados à agregação de resíduos industriais e urbanos na indústria cerâmica representa uma alternativa capaz de contribuir para o uso de matérias-primas alternativas visando a diminuição dos custos finais dos setores industriais, além de preservar o meio ambiente [2, 4-6]. Nesse sentido, a indústria de cerâmica vermelha ganha destaque devido ao seu grande volume de produção, matérias-primas de baixo custo, elevado potencial de incorporação e inertização de resíduos, além de boa tolerância quanto à variabilidade das condições de processamento e variações de composição de suas matérias-primas sem alterações drásticas nas propriedades do produto final [7-9].

Muitos resíduos já foram agregados à matriz cerâmica: cinzas da casca de arroz, de lixívia de glicerina, de serragem, de granitos, de borra oleosa da produção de petróleo, resíduo oleoso da produção de azeite de oliva, resíduos gerados da produção do alumínio, adição de pó de madeira e resíduos de celulose [4, 10-14]. Além disso, um resíduo muito estudado é o vidro, que é classificado como classe II - inerte. O uso de resíduos provenientes da reciclagem de vidro em geral é uma possibilidade a ser explorada, pois a reciclagem e reutilização do vidro contribuem para a matriz energética nacional com a economia de grande quantidade de energia. Para a obtenção de vidros a partir de matérias-primas (originais) naturais e/ ou sintéticas são necessários $4500 \mathrm{~kJ} / \mathrm{kg}$ de vidro produzido, enquanto que para a obtenção de produtos de vidro a partir da sua reciclagem necessita-se somente $500 \mathrm{~kJ} / \mathrm{kg}$ de vidro produzido [15]. Os resíduos da indústria do vidro e de embalagens de vidro usadas no dia a dia são na sua maioria descartados com o lixo doméstico. Os grandes volumes depositados em aterros sanitários acabam gerando problemas ambientais como a contaminação do solo e elevação do $\mathrm{pH}$ e turbidez dos corpos hídricos [16]. Nos materiais cerâmicos há a possibilidade de incorporar o pó de vidro substituindo, por exemplo, o feldspato, conferindo resistência mecânica ao produto final além de não causar prejuízos às demais propriedades do novo material cerâmico obtido [16, 17]. Por outro lado, a erva-mate (Ilex paraguariensis) possui resíduos significativos tanto do cultivo quanto do consumo, em regiões temperadas e subtropicais do Brasil, Paraguai e Argentina [18-22]. A produção de erva-mate é significativa; por exemplo, o Brasil produz 860 mil toneladas por ano, seguido por Argentina que produz 690 mil toneladas e pelo Paraguai que produz 85 mil toneladas [23]. Um estudo [23] mostra a utilização de resíduos de erva-mate como agente formador de poros de espumas vítreas com sucesso. Neste caso $10-30 \%$ de erva-mate foram utilizados em uma mistura com resíduos de vidros sodo-cálcicos, gerando até $88 \%$ de porosidade [23]. Com a adição de resíduos industriais e agroindustriais em matriz cerâmica é possível obter uma alternativa para a redução dos impactos ambientais causados pela extração e beneficiamento de matérias-primas não renováveis, além de utilizar resíduos que seriam descartados no meio ambiente, desta forma agregando valor aos mesmos e originando novos materiais com um menor custo de produção [11, 24]. Dentro deste contexto, o objetivo deste trabalho é a valoração de resíduos de vidros sodo-cálcicos e erva-mate pós-infusão em matriz cerâmica buscando alternativa para a destinação destes resíduos concomitante à produção de novos materiais cerâmicos, os quais tenham propriedades semelhantes aos produzidos comercialmente, sem a adição de resíduos.

\section{MATERIAIS E MÉTODOS}

As matérias-primas utilizadas neste trabalho foram argila, pó de vidros de descarte e erva-mate após infusão. A argila utilizada foi fornecida por uma indústria cerâmica da cidade de Candelária/RS. O pó de vidro foi obtido de vidros de garrafa com diferentes colorações (âmbar, verde e transparente) provenientes do descarte em coleta seletiva. O resíduo de erva-mate utilizado foi obtido da coleta seletiva específica para erva-mate após infusão, disponível na universidade. Inicialmente, a argila foi seca à temperatura ambiente por $24 \mathrm{~h}$ e, em seguida, foi seca em estufa a $110^{\circ} \mathrm{C}$, por $24 \mathrm{~h}$. Posteriormente foi submetida ao processo de moagem em um jarro de porcelana, contendo bolas de alumina, por aproximadamente $2,5 \mathrm{~h}$ em moinho rápido de laboratório (Servitech, CT-242) até o pó ficar $100 \%$ passante em peneira $80 \mathrm{mesh}$. Os vidros foram inicialmente higienizados e secos em estufa (Marte, MB150/6) por $24 \mathrm{~h}$ a $110^{\circ} \mathrm{C}$. Em seguida foram quebrados com martelo e moídos por aproximadamente $2 \mathrm{~h}$ no moinho rápido de laboratório até obter pó $100 \%$ passante em peneira 80 mesh. O resíduo de erva-mate utilizado possuiu um conteúdo de sólidos voláteis de aproximadamente $81 \%$, indicando presença de matéria orgânica. Além disso, possuiu um teor de cinzas de aproximadamente $6 \%$ e um teor de carbono fixo de aproximadamente $13 \%$, que foi relacionado à massa do material remanescente após a remoção dos componentes voláteis durante a queima, excluindo cinzas e umidade. A erva-mate foi peneirada em peneira com abertura 7 mesh a fim de remover resíduos superiores a $2 \mathrm{~mm}$. Posteriormente foi seca na estufa a $110^{\circ} \mathrm{C}$ por aproximadamente $6 \mathrm{~h}$, até estabilização da massa. A caracterização química dos pós de argila, vidro e erva-mate foi realizada utilizando espectroscopia de fluorescência de raios X (Shimadzu, FRX 1800).

Foram formuladas e avaliadas diferentes composições, variando as porcentagens de argila (A), pó de vidro (V) e erva-mate (E): $100 \% \mathrm{~A} ; 80 \% \mathrm{~A}-20 \% \mathrm{~V} ; 70 \% \mathrm{~A}-20 \% \mathrm{~V}-10 \% \mathrm{E}$; $65 \% \mathrm{~A}-20 \% \mathrm{~V}-15 \% \mathrm{E} ; \quad 60 \% \mathrm{~A}-20 \% \mathrm{~V}-20 \% \mathrm{E} ; \quad 55 \% \mathrm{~A}-20 \% \mathrm{~V}-$ $25 \% \mathrm{E}$. Todas as composições formuladas foram umidificadas com 5\% de água, homogeneizadas em moinho rápido de laboratório durante $3 \mathrm{~min}$ e posteriormente compactadas uniaxialmente em 5 ton (Nowak, PH30) em matriz de aço $(6 \times 2 \times 0,5 \mathrm{~cm})$. Após conformação, os corpos de prova foram secos na estufa a $110{ }^{\circ} \mathrm{C}$ por $24 \mathrm{~h}$ e, então, foram queimados em um forno tipo mufla (Jung, 9613), com taxa de $2,5{ }^{\circ} \mathrm{C} \cdot \mathrm{min}^{-1}$ a 900 e $1100{ }^{\circ} \mathrm{C}$ e resfriados inercialmente. 10 corpos de prova de cada composição formulada foram avaliados quanto à retração linear, absorção de água, porosidade aparente e resistência mecânica.

A retração linear dos compactos foi obtida para cada 
condição de tratamento térmico, conforme norma ASTM C 210/95 [25]. As dimensões das amostras foram mensuradas antes e depois do processo de queima, com um paquímetro digital (Mitutoyo, CD-6" CSX-B). A retração linear de queima (RLQ) foi calculada por meio de:

$$
\operatorname{RLQ}(\%)=\left(\frac{\mathrm{L}_{\mathrm{i}}-\mathrm{L}_{\mathrm{f}}}{\mathrm{L}_{\mathrm{f}}}\right)
$$

onde $\mathrm{L}_{\mathrm{i}}$ é a medida do diâmetro da amostra não tratada termicamente $(\mathrm{mm})$ e $\mathrm{L}_{\mathrm{f}}$ é a medida do diâmetro da amostra tratada termicamente ( $\mathrm{mm}$ ). Os ensaios de absorção de água e porosidade aparente seguiram a norma ASTM C 373/94 [26]. O teste de absorção de água (AA) foi realizado por meio da imersão das amostras em água por $24 \mathrm{~h}$. Foram analisadas as massas antes da imersão, após a imersão e ainda saturado, e da amostra imersa em água. Para esta análise foi utilizada a Eq. B:

$$
\operatorname{AA}(\%)=\left(\frac{M_{u}-M_{s}}{M_{s}}\right) \cdot 100
$$

onde Mu é a massa da amostra saturada com água (g) e Ms é a massa da amostra após secagem ( $\mathrm{g}$ ). Para a determinação da porosidade aparente (PA), foram utilizadas as mesmas medidas de massa que foram realizadas na análise de absorção de água e a análise foi feita com base na Eq. C:

$$
\operatorname{PP}(\%)=\left(\frac{M_{u}-M_{s}}{M_{u}-M_{i}}\right) \cdot 100
$$

onde Mi é a massa da amostra imersa em água (g). Amostras foram seccionadas e a superfície de fratura foi analisada em microscópio óptico (Olympus, 3Z61). Para determinar a resistência mecânica das amostras após a queima, ensaios de flexão em quatro pontos foram realizados utilizando uma máquina universal de ensaios (Emic, DL10000) com célula de carga de $50 \mathrm{kN}$, velocidade de ensaio de 0,5 mm.min-1 e início de ensaio em 2 N, seguindo a norma ASTM C 133/97 [27].

\section{RESULTADOS E DISCUSSÃO}

A composição química da argila, do vidro e da erva-mate obtida por fluorescência de raios-X (FRX) está descrita na Tabela I. Foi possível observar que a argila foi composta basicamente por sílica $\left(\mathrm{SiO}_{2}\right)$ e alumina $\left(\mathrm{Al}_{2} \mathrm{O}_{3}\right)$. A razão molar $\mathrm{SiO}_{2} / \mathrm{Al}_{2} \mathrm{O}_{3}$ foi 4,17 . Esse valor é relativamente elevado se comparado ao valor teórico $(2,0)$ calculado para a caulinita, o que sugeriu a presença de quartzo e outros silicatos. Os demais óxidos presentes, como $\mathrm{Fe}_{2} \mathrm{O}_{3}, \mathrm{~K}_{2} \mathrm{O}, \mathrm{MgO}, \mathrm{CaO}$ e $\mathrm{P}_{2} \mathrm{O}_{5}$, apareceram em níveis quase que residuais. Esta argila pôde ser considerada como uma típica matéria-prima para cerâmica vermelha, pois apresentou concentrações de $\mathrm{SiO}_{2}, \mathrm{Fe}_{2} \mathrm{O}_{3}$ e $\mathrm{Al}_{2} \mathrm{O}_{3}$ nas faixas, respectivamente, de 43,2 a $77,6 \%, 1,36$ a $9,6 \%$ e 9,9 a $38 \%$, valores característicos de uma argila vermelha [28]. Notou-se que a argila utilizada foi pobre em óxidos fundentes (ex: $\mathrm{K}_{2} \mathrm{O}, \mathrm{Na}_{2} \mathrm{O}$ ). Isto permitiu prever dificuldades de sinterização em fase líquida. A adição de qualquer tipo de vidro a esta massa eleva os teores de óxidos fundentes. Por outro lado, pôde-se verificar que o vidro utilizado foi composto principalmente de $\mathrm{SiO}_{2}, \mathrm{Na}_{2} \mathrm{O}$ e $\mathrm{CaO}$ em quantidades normalmente encontradas em vidros sodo-cálcicos. $\mathrm{O}$ óxido de ferro $\left(\mathrm{Fe}_{2} \mathrm{O}_{3}\right)$ e o $\mathrm{Cr}_{2} \mathrm{O}_{3}$ presentes nas amostras de vidro foram devidos à coloração verde ou âmbar das garrafas de vidro utilizadas, já que estes são agentes cromóforos. $\mathrm{O}$ vidro sodo-cálcico desempenha papel de fundente e mantêm a viscosidade do vidro em um determi-

\begin{tabular}{|c|c|c|c|c|c|c|}
\hline Óxido & Argila & Vidro transparente & Vidro verde & Vidro âmbar & Mistura dos vidros & Erva-mate \\
\hline $\mathrm{SiO}_{2}$ & 64,27 & 71,25 & 71,06 & 71,14 & 71,10 & 0,7 \\
\hline $\mathrm{Al}_{2} \mathrm{O}_{3}$ & 15,40 & 1,77 & 1,99 & 1,71 & 1,84 & 0,3 \\
\hline $\mathrm{Fe}_{2} \mathrm{O}_{3}$ & 5,23 & 0,21 & 0,44 & 0,51 & 0,39 & 0,5 \\
\hline $\mathrm{CaO}$ & 0,32 & 11,59 & 10,76 & 10,92 & 11,11 & 1,2 \\
\hline $\mathrm{K}_{2} \mathrm{O}$ & 2,46 & 0,22 & 0,31 & 0,36 & 0,30 & 1,7 \\
\hline $\mathrm{MgO}$ & 0,78 & 0,50 & 0,84 & 0,90 & 0,74 & 0,3 \\
\hline $\mathrm{Na}_{2} \mathrm{O}$ & - & 13,67 & 13,74 & 13,62 & 13,71 & - \\
\hline $\mathrm{P}_{2} \mathrm{O}_{5}$ & 0,10 & $<0,05$ & $<0,05$ & $<0,05$ & $<0,05$ & 0,3 \\
\hline $\mathrm{TiO}_{2}$ & 0,78 & $<0,05$ & $<0,05$ & $<0,05$ & $<0,05$ & \\
\hline $\mathrm{MnO}$ & 0,06 & - & - & - & - & 0,2 \\
\hline $\mathrm{SO}_{3}$ & - & - & - & - & - & 0,4 \\
\hline $\mathrm{BaO}$ & - & 0,13 & 0,13 & 0,08 & 0,08 & - \\
\hline $\mathrm{ZnO}$ & 0,01 & - & - & - & - & - \\
\hline $\mathrm{SrO}$ & 0,02 & - & - & - & - & - \\
\hline $\mathrm{Cr}_{2} \mathrm{O}_{3}$ & - & $<0,10$ & 0,28 & $<0,10$ & 0,12 & - \\
\hline Perda ao fogo & 10,58 & - & - & - & - & 94,3 \\
\hline
\end{tabular}

Tabela I - Análise química (FRX) dos resíduos de vidro, erva-mate e de argila (\% em massa).

[Table I-Chemical analysis (X-ray fluorescence) of the glass waste, yerba mate, and clay (wt\%).] 
nado patamar em um largo intervalo de temperatura. Já a erva-mate foi rica em $\mathrm{CaO}, \mathrm{K}_{2} \mathrm{O}, \mathrm{SiO}_{2}, \mathrm{MnO}, \mathrm{P}_{2} \mathrm{O}_{5}$ e $\mathrm{MgO}$. Esses componentes foram em acordo com estudos anteriores [28], e suas presenças possivelmente não afetam significativamente o desempenho do produto cerâmico final obtido porque apresentam baixas concentrações.

A Fig. 1a mostra os resultados de retração linear para as amostras obtidas. Observou-se que tanto para o incremento da temperatura quanto para a adição de resíduos ocorreu um aumento da retração linear das amostras. Para as amostras queimadas a $900{ }^{\circ} \mathrm{C}$ a retração linear variou de 0,3 a $2,3 \%$ e para as amostras queimadas a $1100{ }^{\circ} \mathrm{C}$ a retração linear
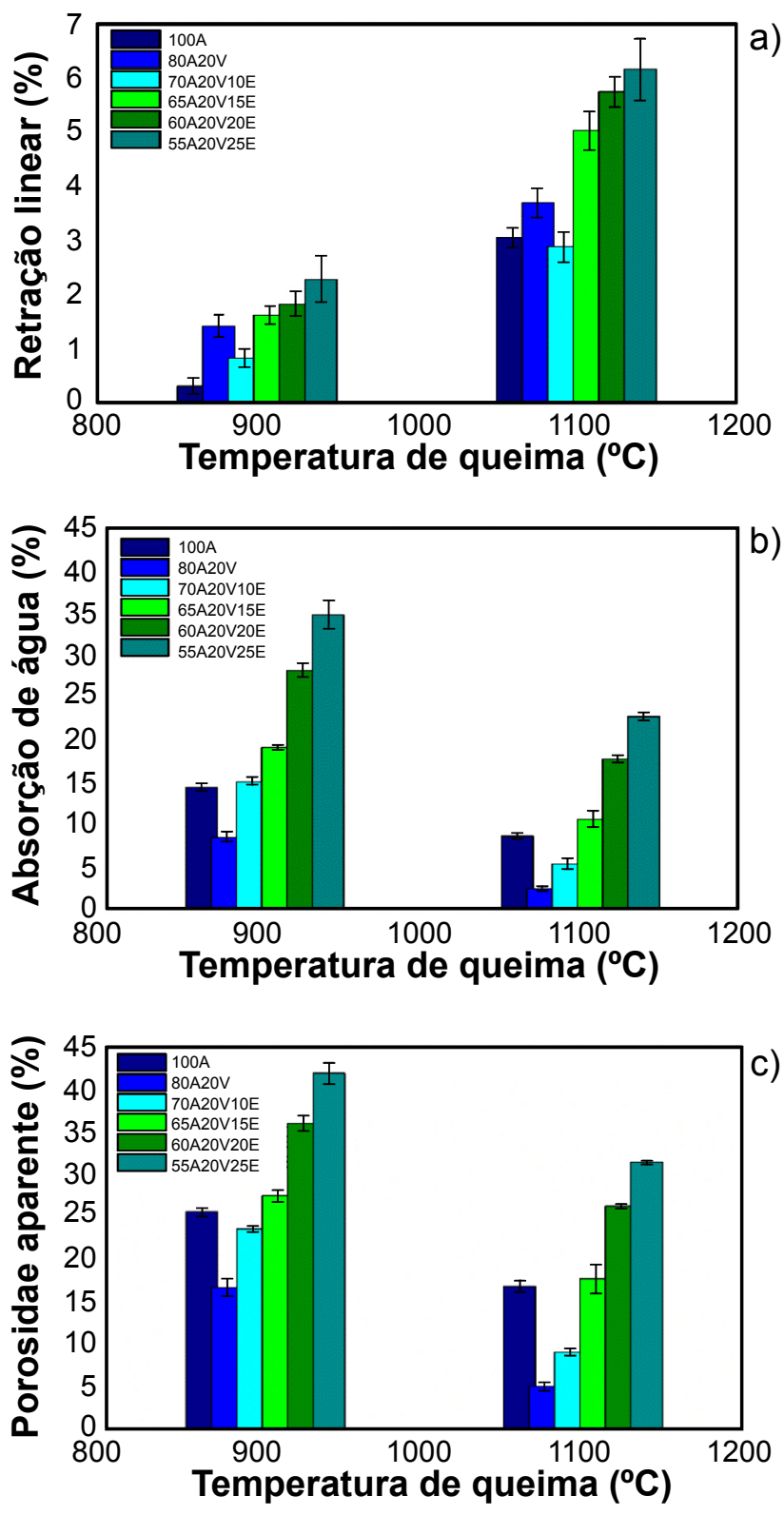

Figura 1: Retração linear (a), absorção de água (b) e porosidade aparente (c) das amostras obtidas com diferentes adições de resíduos de vidro sodo-cálcico e erva-mate queimadas a 900 e $1100{ }^{\circ} \mathrm{C}$.

[Figure 1: Linear shrinkage (a), water absorption (b), and apparent porosity $(c)$ of the samples obtained with different additions of sodalime glass and yerba mate wastes fired at 900 and $\left.1100{ }^{\circ} \mathrm{C}.\right]$ variou de 3 a $6,1 \%$. Nos dois casos, a retração linear aumentou com a adição de vidro quando comparada à argila sozinha. Este fato foi relacionado à maior quantidade de fundentes presentes no vidro que auxiliaram no processo de sinterização [29]. O aumento da quantidade de erva-mate na formulação fez com que a retração linear aumentasse devido principalmente à degradação destes materiais com o incremento da temperatura. $\mathrm{O}$ aumento da retração linear com o aumento da temperatura foi relacionado a uma maior sinterização das amostras devido às características da massa formulada [30]. Ou seja, parte da massa se transformou em um líquido viscoso (vidro) que escorreu e ocupou os espaços vazios entre as partículas mais refratárias (matriz cerâmica) e dessa forma reduziu a porosidade aberta (ocasionada também pela degradação da erva-mate) e, devido às forças de capilaridade, provocou a aproximação das partículas, o que levou à retração. Durante o resfriamento, esse material líquido viscoso se transformou em um vidro que ligou as partículas mais refratárias e aumentou a resistência mecânica do que era, antes da queima, só um compactado de partículas.

A Fig. $1 \mathrm{~b}$ mostra a absorção de água das amostras obtidas. Foi possível observar que, no geral, as amostras queimadas em $900{ }^{\circ} \mathrm{C}$ possuíram uma maior absorção em comparação às amostras queimadas em $1100^{\circ} \mathrm{C}[31,32]$. Este fato pode ser explicado pela porosidade do material, característico da queima a esta temperatura mais baixa. Aumentando-se a temperatura de queima para $1100{ }^{\circ} \mathrm{C}$ percebeu-se uma redução nos valores de absorção de água, o que era esperado, já que a porosidade aberta foi menor devido à formação de uma fase vítrea nestas condições, auxiliando na sinterização. Por sua vez, a amostra com adição de vidro (80A20V), quando comparada à argila pura possuiu uma menor absorção de água. Diversos trabalhos na literatura [16, 29, 33] demonstram esse comportamento relacionando a menor absorção de água de amostras contendo resíduos de vidro reciclado com uma melhor sinterização. Por outro lado, a adição e o aumento do teor de erva-mate nas amostras elevaram os valores absorção de água, já que a erva-mate foi degradada com o incremento da temperatura, restando apenas a matriz cerâmica com vidro. Vale salientar que quanto maior a quantidade de erva-mate adicionada, maior foi a absorção de água. Segundo as normas da Associação Brasileira de Normas Técnicas (ABNT), os resultados de absorção de água servem como parâmetro para a classificação do material e sua utilização como telhas ABNT NBR 15310:2009 ( $\leq 18 \%$ ) [34], blocos cerâmicos ABNT NBR 15270-3:2005 (8 a 18\%) [35] e placas cerâmicas de revestimento ABNT NBR 13818:1997 (0,5 a 10\%) [36]. Se observada apenas a absorção de água, as amostras obtidas contendo até $20 \%$ de erva-mate e $20 \%$ de vidro sodo-cálcico, queimadas em $1100^{\circ} \mathrm{C}$, podem ser utilizadas na produção de telhas e blocos cerâmicos. Por outro lado, as amostras contendo uma menor quantidade de resíduos (10 e 15\% de erva-mate) queimadas a $1100{ }^{\circ} \mathrm{C}$ podem ser utilizadas inclusive para a produção de placas de revestimento. A Fig. 1c mostra os resultados de porosidade aparente das amostras obtidas. Para a temperatu- 
ra de $900{ }^{\circ} \mathrm{C}$ foram alcançadas porosidades aparentes entre 16,5 e $42 \%$. Para a temperatura de $1100{ }^{\circ} \mathrm{C}$ foram alcançadas porosidades entre 5 e $31,5 \%$. Os resultados foram em bom acordo com os valores de absorção de água, ou seja, uma menor porosidade aparente foi obtida para amostras queimadas a $1100^{\circ} \mathrm{C}[30,31]$. Além disso, a redução da porosidade aparente para a amostra contendo $20 \%$ de vidro e $10 \%$ de erva-mate, com relação à amostra contendo apenas argila, foi devido ao aumento da formação de fase vítrea, que auxiliou na sinterização, diminuindo a porosidade aberta [9, 32, 37].

A Fig. 2 mostra imagens de microscopia óptica das amostras obtidas a partir de argila, adições de resíduos de

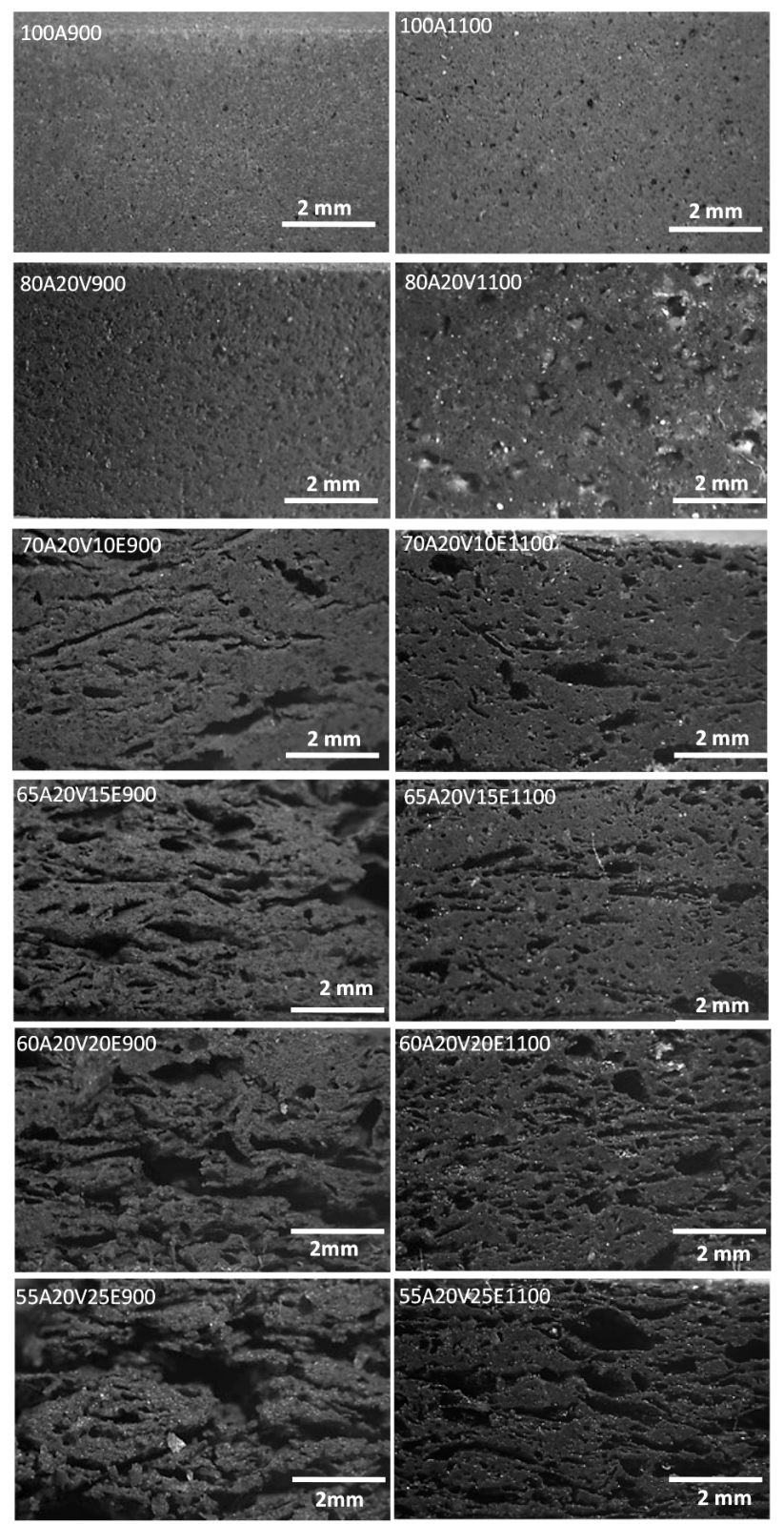

Figura 2: Imagens de microscopia óptica das amostras obtidas com diferentes adições de resíduos de vidro sodo-cálcico e argila e erva-mate queimadas em 900 e $1100{ }^{\circ} \mathrm{C}$.

[Figure 2: Optical microscopy images of the samples obtained with different additions of soda-lime glass and yerba mate wastes fired at 900 and $\left.1100{ }^{\circ} \mathrm{C}.\right]$ vidro sodo-cálcico e erva-mate queimadas em 900 e $1100{ }^{\circ} \mathrm{C}$. Observou-se uma melhor homogeneidade estrutural e menor quantidade de poros para as amostras contendo somente argila e para as amostras contendo adições de vidro sodocálcico. $\mathrm{O}$ incremento da quantidade de erva-mate aumentou também a porosidade, o que já era esperado e foi de acordo com os resultados calculados para porosidade aparente (Fig. 2). Observou-se também que as amostras queimadas em $1100{ }^{\circ} \mathrm{C}$ apresentaram uma menor porosidade e, neste caso, os poros foram majoritariamente fechados, justificando a menor absorção de água para as amostras queimadas nessa temperatura. Nas amostras queimadas a $900{ }^{\circ} \mathrm{C}$ a maioria dos poros foi interconectada. A $1100{ }^{\circ} \mathrm{C}$ observou-se uma melhor sinterização da matriz cerâmica. Além disso, foi possível observar que as amostras queimadas a $1100{ }^{\circ} \mathrm{C}$ possuíram uma melhor homogeneidade microestrutural se comparadas com as amostras queimadas a $900{ }^{\circ} \mathrm{C}$. Essa melhor homogeneidade microestrutural pode refletir em uma melhoria nas propriedades mecânicas.

A Fig. 3 mostra a resistência mecânica das amostras obtidas. Foram obtidos valores de resistência mecânica desde 0,5 a aproximadamente $20 \mathrm{MPa}$. A resistência mecânica é muito sensível à porosidade e, neste caso, foi dominada por ela, pois houve uma clara relação entre a diminuição da resistência mecânica e o aumento da absorção de água. Um aumento da resistência mecânica foi observado para as amostras com adição de vidro devido a melhor sinterização destas amostras [17]. Pôde-se observar que a resistência mecânica diminuiu com o incremento da quantidade de erva-mate na matriz para ambas as temperaturas de queima, o que era esperado já que o resíduo de erva-mate aumentou a porosidade do material. Por outro lado, o incremento da temperatura de 900 para $1100{ }^{\circ} \mathrm{C}$ aumentou consideravelmente a resistência mecânica, o que foi relacionado à melhor sinterização das amostras nesta temperatura de queima [38-40]. A classificação quanto à resistência mecânica, de acordo com a ABNT, para telhas

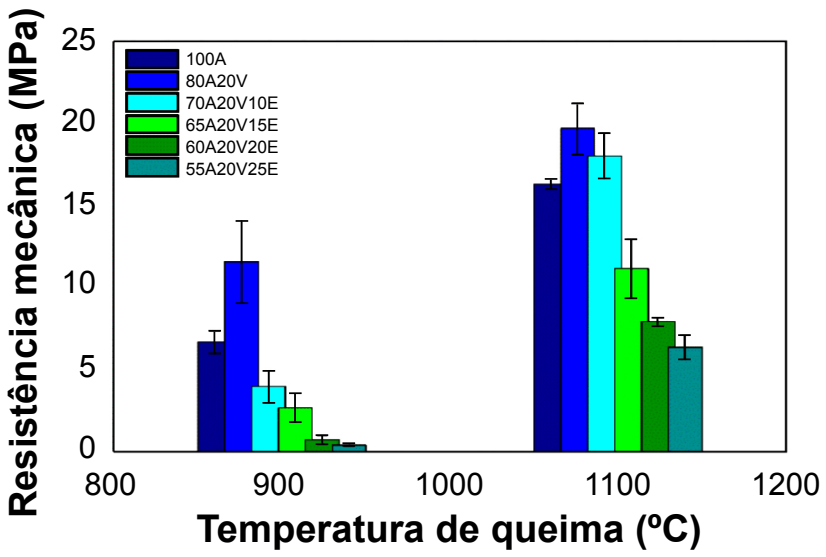

Figura 3: Resistência mecânica das amostras obtidas com diferentes adições de resíduos de vidro sodo-cálcico e erva-mate queimadas em 900 e $1100{ }^{\circ} \mathrm{C}$

[Figure 3: Mechanical strength of the samples obtained with different additions of soda-lime glass and yerba mate wastes fired at 900 and $1100{ }^{\circ} \mathrm{C}$.] 
ABNT NBR 15310:2009 varia entre 6,8 e 9,9 MPa e máx. 12,7 MPa [34], para blocos cerâmicos ABNT NBR 152703:2005 de no mínimo $1 \mathrm{MPa}$ [35] e para placas cerâmicas de revestimento ABNT NBR 13818:1997 varia entre 15 e 35 MPa ou superior [36]. Considerando a resistência mecânica os materiais queimados em $1100{ }^{\circ} \mathrm{C}$ podem ser utilizados tanto na fabricação de blocos cerâmicos, telhas ou placas de revestimento.

\section{CONCLUSÕES}

Foram obtidos materiais cerâmicos a partir da adição de resíduos de vidro sodo-cálcicos e erva-mate à argila, queimados a 900 e $1100{ }^{\circ} \mathrm{C}$ com retração linear entre 0,3 e $6 \%$, absorção de água entre 0,5 e $34 \%$, porosidade aparente de até $41 \%$ e resistência mecânica variando entre 0,5 e $25 \mathrm{MPa}$. Os materiais queimados a $1100{ }^{\circ} \mathrm{C}$ foram os que apresentaram as melhores combinações de propriedades, podendo ser aplicados na produção de blocos, telhas ou revestimento cerâmico de acordo com as necessidades especificas da aplicação, mesmo quando comparados à formulação que não continha o resíduo de erva-mate. Os resultados deste trabalho apontaram uma forma de valoração dos resíduos até então não muito utilizados, como o caso da erva-mate pós-infusão. Ainda, a obtenção destes novos materiais cerâmicos com potencial utilização aos industrialmente comercializados é tecnicamente viável, além de ser uma alternativa para aplicação destes resíduos, que poderiam causar danos se descartados no meio ambiente, além de gerar interessante redução da extração de matéria-prima da natureza.

\section{AGRADECIMENTOS}

Os autores gostariam de agradecer especialmente às agências de fomento CNPq (Processo $\mathrm{n}^{\circ}$ 427402/20166 - Chamada CNPq/Universal $\mathrm{n}^{\circ}$ 01/2016), CAPES e FAPERGS.

\section{REFERÊNCIAS}

[1] J.G.M. Peres, R.D. Tavares, S.Q.J. de Luca, P.I. Barbosa, I. de Cássia Tacão, Eng. Amb. Pesq. Tec. 10, 4 (2013).

[2] B. Braga, Introdução à engenharia ambiental, $2^{\mathrm{a}}$ ed., Person Prentice Hall, S. Paulo (2005).

[3] P. Zhang, J. Huang, Z. Shen, X. Wang, F. Luo, P. Zhang, J. Wang, S. Miao, Constr. Build. Mater. 141 (2017) 435.

[4] D. Collatto, C.P. Bergmann, M.V.V. Ramires. Est. Tecn. Eng. 4, 1 (2008) 1.

[5] A.F. Lemos, J.M.F. Ferreira, in: Anais $45^{\circ}$ Congr. Bras. Cerâm. 30 (2001).

[6] A.C.M. Rodrigues, O. Peitl, in: El reciclado vidrio Iberoam., CYTED, Madrid (1999) 33.

[7] R.V. Silva, J. de Brito, C.Q. Lye, R.K. Dhir, J. Clean. Prod. 167 (2017) 346.

[8] H.N. Souza, E.L. Reis, R.M.F. Lima, R.A.S. Cipriano, Ceram. Int. 42, 14 (2016) 16205.

[9] R.R. Menezes, G.A. Neves, H.C. Ferreira, Rev. Bras.
Eng. Agr. Amb. 6, 2 (2002) 303.

[10] R.P.S. Dutra, L.R. de Araújo Pontes, Cerâmica 48, 308 (2002) 308.

[11] D. Eliche-Quesada, S. Martínez-Martínez, L. PérezVillarejo, F.J. Iglesias-Godino, C. Martínez-García, F.A. Corpas-Iglesias, Fuel Process. Technol. 103 (2012) 166.

[12] S. Martínez-Martínez, L. Pérez-Villarejo, D. ElicheQuesada, B. Carrasco-Hurtado, P.J. Sánchez-Soto, G.N. Angelopoulos, Appl. Clay Sci. 121 (2016) 119.

[13] D. Eliche-Quesada, F.A. Corpas-Iglesias, L. PérezVillarejo, F.J. Iglesias-Godino, Constr. Build. Mater. 34 (2012) 275

[14] A. José, M. Lorite, J. Jiménez, E. Castro, J. Hazard. Mat. 169, 1 (2009) 271.

[15] L.B. Teixeira, B.G.D.O. Maia, S. Arcaro, N. Sellin, A.P.N.D. Oliveira, Matéria 22, 4 (2017).

[16] A. Luz, S. Ribeiro, Matéria 13, 1 (2008) 96.

[17] K.O. Godinho, J.N.F. Holanda, A.G.P. Silva, Cerâmica 51 (2005) 420.

[18] S. Arcaro, B.G.O. Maia, M.T. Souza, F.R. Cesconeto, L. Granados, A.P.N. Oliveira, Mater. Res. 19, 5 (2016) 1064. [19] E.L.C. Junior, C. Morand, J. Funct. Foods 21 (2016) 440.

[20] B.O. Caron, D.R. Santos, D. Schmidt, C.J. Basso, A. Behling, E. Eloy, R. Bamberg, Ciênc. Florest. 24, 2 (2014) 267.

[21] Y.M.M. de Oliveira, E. Rotta, in: Seminário sobre atualidades e perspectivas florestais, Embrapa-CNPF (1985) 17.

[22] F. Braghini, C.G. Carli, B. Bonsaglia, J.F. Santos, S. Junior, D.F. Oliveira, J. Tramujas, I. B. Tonial, Pesq. Agropec. Gaúcha 20 (2014) 7.

[23] G. Santacruz, S. Arcaro, A.K. Alves, C.P. Bergmann, FME Transact. 46, 1 (2018) 71.

[24] S.P. Raut, R.V. Ralegaonkar, S.A. Mandavgane, Constr. Build. Mater. 25, 10 (2011) 4037.

[25] ASTM, "Standard test method for reheat change of insulating firebrick", ASTM C 210, Philadelphia (1995).

[26] ASTM, "Test method for water absorption, bulk density and aparent porosity", ASTM C 373, Philadelphia (1994).

[27] ASTM, "Test method for crushing strenght and modulus of rupture of refractories", ASTM C 133, Philadelphia (1995).

[28] S. Sousa, Ciência e tecnologia de argilas, Edgard Blucher, S. Paulo (1989).

[29] K. Godinho, J. Holanda, A. Da Silva, Cerâmica 51, 320 (2005) 420

[30] W. Acchar, F.A. Vieira, A.M. Segadães, Mater. Sci. Eng. A 435-436 (2006) 606.

[31] A.E. Souza, S.R. Teixeira, G.T.A. Santos, F.B. Costa, E. Longo, J. Environ. Manage. 92, 10 (2011) 2774.

[32] S.R. Teixeira, G.T.A. Santos, A.E. Souza, P. Alessio, S.A. Souza, N.R. Souza, Appl. Clay Sci. 53, 4 (2011) 561.

[33] C.M.F. Vieira, A.S.C. Morais, S.N. Monteiro, G.C.G. Delaqua, Cerâmica 62, 364 (2016) 376.

[34] ABNT, "Componentes cerâmicos - telhas terminologia, requisitos e métodos de ensaio", ABNT NBR 
15310, Brasil (2009).

[35] ABNT, "Componentes cerâmicos - parte 3: blocos cerâmicos para alvenaria estrutural e de vedação - métodos de ensaio", ABNT NBR 15270-3, Brasil (2005).

[36] ABNT, "Placas cerâmicas para revestimento especificação e métodos de ensaios", ABNT NBR 13818, Brasil (1997).

[37] A.C. Teloeken, D. Villanova, T. Basegio, C. Bergmann,
Cerâm. Ind. 16, 2 (2011) 14.

[38] L. Wiemes, U. Pawlowsky, V. Mymrin, J. Clean. Prod. 142 (2017) 69.

[39] N. Phonphuak, S. Kanyakam, P. Chindaprasirt, J. Clean. Prod. 112 (2016) 3057.

[40] H. Zouaoui, J. Bouaziz, Appl. Clay Sci. 150 (2017) 131.

(Rec. 03/02/2018, Rev. 10/03/2018, 30/05/2018, Ac. $15 / 08 / 2018)$ 